\title{
Remembrance of Things Past
}

\section{Martin Bloom ${ }^{1}$}

Published online: 2 March 2007

[The Journal of Primary Prevention, 28(1), 3-5 (2007)]

In the original article on pages 3-4, the author cites the following quotation: "Public health teaches us that no mass disease or disorder has ever been controlled or eliminated through individual treatment or by increasing the number of therapists" (Albee, 2005, p. 37). This section of text should read: "Public health teaches us that no mass disease or disorder has ever been controlled or eliminated through individual treatment" (Albee, 2006, p. 449) or by increasing the number of therapists. The correct citation is: Albee, G. W. (2006). Historical overview of primary prevention of psychopathology: Address to The 3rd World Conference on the Promotion of Mental Health and Prevention of Mental and Behavioral Disorders September 15-17, 2004, Auckland, New Zealand. The Journal of Primary Prevention, 27(5), 449-456.

The online version of the original article can be found at http://dx.doi.org/10.1007/s10935-006-0068-2.

\footnotetext{
${ }^{1}$ Address correspondence to Martin Bloom, 70 Southworth Drive, Ashford, CT 06278, USA; e-mail: martin.bloom@uconn.edu.
} 